\title{
Doppelte RAS-Blockade mit Risiken
}

Fragestellung: In der vorliegenden Studie wurde untersucht, inwiefern der Gebrauch eines direkten Renin-Inhibitors (Aliskiren) in der Lage ist, kardiovaskuläre und renale Endpunkte bei Patienten mit Diabetes mellitus Typ 2 und chronischer Niereninsuffizienz zu verringern.

Methoden: Es handelte sich um eine Doppelblindstudie, in der 8561 Patienten entweder Aliskiren (3 mg/d) oder Placebo in Kombination mit einem ACE-Inhibitor oder einem Angiontensin-Rezeptor-Blocker behandelt wurden.

Primärer Endpunkt war kardiovaskulärer Tod oder Herzstillstand mit Reanimation, Myokardinfarkt, Schlaganfall, Hospitalisierung aufgrund einer Herzinsuffizienz, dialysepflichtige Niereninsuffizienz oder Todesfälle aufgrund von Nierenisuffizienz sowie die Verdopplung des Serum-Kreatinin-Werts.

Ergebnisse: Die Studie wurde nach einer zweiten Zwischenauswertung vorzeitig beendet. Nach einer medianen Beobachtungszeit von 32,9 Monaten wurde der primäre Endpunkt bei $783 \mathrm{~Pa}$ - tienten (18,3\%) der Aliskiren-Grupe und in der Placebo-Gruppe bei 732 Patienten (17,1\%) beobachtet.

Der systolische und diastolische Blutdruck war in der Aliskiren-Gruppe niedriger, ebenso zeigte sich eine deutlichere Verringerung der Urin-Albumin-Ausscheidung in der Verum-Gruppe. Interessanterweise hatten in der Aliskiren-Gruppe mehr Patienten eine Hyperkaliämie (Serum-Kalium-Wert $\geq 6 \mathrm{mmol} / \mathrm{l}$ ). Ebenso wurden in der Aliskiren-Gruppe signifikant häufiger Hypotensionen beobachtet.

Schlussfolgerung: Die zusätzliche Gabe von Aliskiren zu einer Standardtherapie mit einem ACE-Hemmer oder einem Angiotensin-Rezeptor-Blocker kann bei Patienten mit Diabetes mellitus Typ 2 aufgrund dieser Studienergebnisse nicht empfohlen werden, denn sie ist mit weiteren Risiken wie Hyperkaliämie verbunden.
Parving $\mathrm{HH}$, Brenner $\mathrm{BM}$, McMurray JJV et al. Cardiorenal End Points in a Trial of Aliskiren for Type 2 Diabetes. N Engl J Med 2012;367:2204-13.

$\mathrm{T} 1$ Primäre und sekundäre Endpunkte und Todesfälle

Primärer Endpunkt

- Tod aufgrund kardiovaskulärer Ursachen

- Herzstillstand mit Reanimation

- Herzinfarkt (tödlich oder nicht tödlich)

- Schlaganfall (tödlich oder nicht tödlich)

- Ungeplante Krankenhausaufenthalte wegen Herzinsuffizienz

- Nierenerkrankung im Endstadium, Tod aufgrund von Nierenversagen oder Nierenfunktionsstörungen

- Verdopplung des Serumkreatinins

Kardiovaskulärer Endpunkt

Renaler Endpunkt

Tod (jegliche Ursachen)

\begin{tabular}{lccc}
$\begin{array}{l}\text { Aliskiren }(\mathrm{n}=4274) \\
\text { Anzahl der Patienten }(\%)\end{array}$ & Placebo $(\mathrm{n}=4287)$ & Hazard Ratio $(95 \%-K I)$ & $\mathrm{p}$-Wert \\
$783(18,3)$ & $732(17,1)$ & $1,08(0,98-1,20)$ & 0,12 \\
$246(5,8)$ & $215(5,0)$ & $1,16(0,96-1,39)$ & 0,12 \\
$19(0,4)$ & $8(0,2)$ & $2,40(1,05-5,48)$ & 0,04 \\
$147(3,4)$ & $142(3,3)$ & $1,04(0,83-1,31)$ & 0,72 \\
$147(3,4)$ & $122(2,8)$ & $1,22(0,96-1,55)$ & 0,11 \\
$205(4,8)$ & $219(5,1)$ & $0,95(0,78-1,14)$ & 0,56 \\
$121(2,8)$ & $113(2,6)$ & $1,08(0,84-1,40)$ & 0,56 \\
$210(4,9)$ & & \\
$590(13,8)$ & $217(5,1)$ & $0,97(0,80-1,17)$ & 0,75 \\
$257(6,0)$ & $539(12,6)$ & $1,11(0,99-1,25)$ & 0,09 \\
$376(8,8)$ & $251(5,9)$ & $1,03(0,87-1,23)$ & 0,74 \\
& $358(8,4)$ & $1,06(0,92-1,23)$ & 0,42 \\
\hline
\end{tabular}

\section{-Kommentar von PD Dr. med. Werner Kleophas}

\section{Bei niereninsuffizienten Typ-2-Diabetikern besser darauf verzichten}

Diese gut angelegte kontrollierte Studie zeigte, dass die Kombination eines direkten Renin-Inhibitors mit einem ACE-Hemmer oder Angiotensin-Rezeptor-Blocker nicht in der Lage ist, das kardiovaskuläre Risiko von Patienten mit Diabetes mellitus Typ 2 und Niereninsuffizienz zu verringern. Im Gegenteil: Risikoreiche Blutdruckabfälle oder Hyperkaliämien wurden signifikant häufiger beobachtet. Nach der ONTARGET-Studie, bei der die Kombination aus ACE-Hemmer und Angiotensin-Rezeptor-Blocker keinen Vorteil hinsichtlich renaler Endpunkte zeigte, wurde hier abermals nachgewiesen, dass die Kombinationstherapie von Substanzklassen, die unterschiedliche Ansatzpunkte am Renin-Angiotensin-Aldosterin-System haben, kritisch zu sehen ist. Diese Erkenntnisse sind für die praktische Arbeit von besonderer Bedeutung.

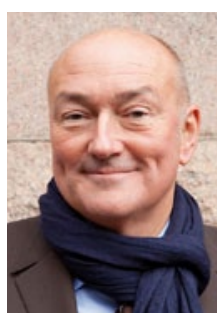

PD Dr. med. Werner Kleophas

Gemeinschaftspraxis Karlstraße

Bismarckstr. 101

D-40210 Düsseldorf

kleophas@praxis-mit-nähe.de 